\title{
Rediscovering Herb Lane: Application of Design Thinking to Enhance Visitor Experience in a Traditional Market
}

\author{
Fang-Wu Tung
}

Citation: Tung, F.-W. Rediscovering Herb Lane: Application of Design Thinking to Enhance Visitor Experience in a Traditional Market. Sustainability 2021, 13, 4033. https:// doi.org/10.3390/su13074033

Academic Editor: Brian Garrod

Received: 28 January 2021

Accepted: 29 March 2021

Published: 5 April 2021

Publisher's Note: MDPI stays neutral with regard to jurisdictional claims in published maps and institutional affiliations.

Copyright: (C) 2021 by the author. Licensee MDPI, Basel, Switzerland. This article is an open access article distributed under the terms and conditions of the Creative Commons Attribution (CC BY) license (https:/ / creativecommons.org/licenses/by/ $4.0 /)$.
Department of Design, National Taiwan University of Science and Technology, Taipei 106335, Taiwan; fwtung@ntust.edu.tw

\begin{abstract}
The need to redevelop depressed traditional markets as cultural tourism attractions has been recognized as urgent in contemporary urban regeneration projects. The survival and development of these marketplaces can support economic prosperity and sociocultural diversity. This study applies design thinking to foster multidisciplinary collaboration and integrate interactive technology with the aim of enhancing visitor experience in Herb Lane, which is a traditional market for traditional Chinese herbs. The practice-based research details the activities and methods to be undertaken to support a multidisciplinary collaboration throughout the design thinking process. The outcome yielded from the process was a mobile application that provides personal herbal recommendations, inspired by traditional Chinese medicine practices and herb-finding activities and supported by visual recognition technology. The mobile application was evaluated through a field trial study, and the results indicate that the mobile application can significantly enhance visitor experience in Herb Lane. This study is expected to contribute to the research and practical knowledge regarding design thinking, multidisciplinary collaboration, and smart tourism. It should also encourage relevant professionals to work together for the continuity and development of traditional markets.
\end{abstract}

Keywords: design thinking; multidisciplinary collaboration; traditional market; tourist experience; research through design

\section{Introduction}

This practice-based research applies design thinking to lead a multidisciplinary team in integrating interactive technology for enhancing visitor experience in Herb Lane, a traditional market for traditional Chinese herbs. Herb Lane, located in Taipei, is the largest marketplace of herbs in Taiwan. The long history of herbs being used as functional foods, owing to their health-maintaining properties, provides an invaluable asset of Taiwan's culture. Food is an essential component of traditional Chinese medicine (TCM) for the prevention and treatment of many diseases. A wide range of dietary herbs has been investigated and incorporated into human diets to maintain general wellness and to prevent certain diseases. Herb Lane is a vivid historic place that has maintained its continuity and manifested cultural heritage over time. However, like many traditional markets, Herb Lane is gradually declining because of changes in distribution systems and changing lifestyles. The use of dietary herbs is less popular in modern society, and there is a gap between the acceptance and knowledge of dietary herbs by young people. Traditional Chinese herbs are usually associated with older adults because the younger generation is not interested or knowledgeable about herbs and their uses. Thus, Herb Lane has a declining market and poor prospects. The dwindling vibrancy of Herb Lane has significantly influenced the urban commercial area, and the culture and history associated with it are expected to disappear in the near future.

The revitalization of traditional markets is an urgent task in contemporary urban regeneration projects [1-3]. The need for the redevelopment of depressed traditional markets, such as Herb Lane, has been recognized by local and central governments because the survival and development of these marketplaces can support economic development 
and sociocultural diversity. A strategy for nurturing a traditional market is to transform it into a tourist attraction based on its local characteristics [4,5]. A traditional market is not just a commercial space, but it is also a cultural space that provides a glimpse of the local lifestyle while preserving its culture [6]. The inherently unique characteristics of these traditional markets can be utilized as a cultural and tourism resource to attract visitors and increase sales, thus sustaining the economic vitality of the market. To reform Herb Lane as a cultural attraction for herbal culture, the Taipei government has renovated the area and installed on-site interpretive panels to provide visitors with some history and current knowledge. Research on tourism has changed from focusing on objects provided by businesses to studying visitors' subjective perceptions and experiences [7]. Thus, to promote Herb Lane as a tourist attraction, attention should be paid to enhancements to the visitor experience [8].

In the era of advanced information and communication technologies, several studies have demonstrated that the integration of technology into cultural and heritage places serves as an effective strategy for enhancing visitor experiences [9-12]. The application of technologies may open new opportunities for Herb Lane to provide visitors with better experiences, facilitating the transition to a cultural attraction and strengthening local commercial activities while considering the cultural vitality of the location. The initiative requires participants from multiple disciplines to inspire innovation and blend technologies into the local context to sustain cultural vitality. A mindset that focuses on the connections across fields to overcome barriers is essential to tackle sustainability issues [13], in which multiple possibilities and constraints can be addressed simultaneously. To perform multidisciplinary collaborations, design thinking is considered to be an effective approach for the integration of multiple disciplines to foster better teamwork and communication toward innovative solutions [14]. Lee [15] introduced design thinking into his curriculum to guide students with diverse interests to generate diverse concepts to revitalize a traditional market in rural Korea. The fruitful outcomes demonstrate the potential of implementing design thinking to foster a multidisciplinary collaboration to address the sustainability of traditional markets.

The design-thinking approach has received attention in the tourism field, providing visitors with a better experience and improving the quality of tourism services [16]. Volgger [17] suggested that the design-thinking methodology can be beneficial for nurturing destination development by pooling different disciplines and actors to gain a fresh understanding of challenges in tourism destinations and propose innovative solutions. Tourism scholars are beginning to adapt the design-thinking methodology to education in order to nurture innovation competencies and problem-solving skills while engaging students in a multidisciplinary collaboration environment $[18,19]$. The book Design Science in Tourism [20] argued that design thinking provides essential tools for guiding tourism design, beginning with understanding and discovery and progressing to ideation and the proposal of solutions. It finally delivers prototypes for evaluation. The design-thinking approach may considerably benefit tourism development [21-23]. However, until recently, research on how to put this approach to use has been limited, mostly providing case studies that merely demonstrate new solutions generated from the process. Design thinking can be valuable not only for concept generation but also for concept selection, prototyping, and evaluation to gain experiential knowledge. Cross [24] coined the phrase "designerly ways of knowing" to highlight the part of design knowledge that is inherent in the activity of the design process. The experiential nature of design knowledge suggests that it can only be obtained by engaging in activities through practicing. Research through design (RtD) employs methods and processes from design practice and is a legitimate method of inquiry in contemporary design research [25]. Bardzell et al. [26] noted that the documentation of RtD processes is essential for capturing and translating design knowledge into broader academic knowledge. Hence, this study adopts the RtD approach to investigate how to apply design thinking by guiding a multidisciplinary team in exploring the potential of technology for enhancing visitor experiences in Herb Lane. The research herein is expected 
to contribute to the discourse regarding design thinking in tourism design while encouraging multiple disciplines and actors to collaborate for the continuity and development of traditional markets.

\section{Literature Review}

\subsection{Design Thinking}

Design thinking is a human-centered problem-solving approach that requires dynamic thinking, empathy, problem identification, idea generation, prototypes, and testing to arrive at a solution $[27,28]$. Design thinking reflects a design approach for tackling problems, and one essential trait is the ability to work with other disciplines and integrate their domain knowledge and experiences to attain the design goal. Olsen [29] defined design thinking as a process that engages a broad range of players to identify the problem and provide a solution. A multidisciplinary collaboration comprises people from different intellectual and disciplinary backgrounds that may complement each other while promoting the emergence of innovative ideas. Ideally, it is a process of creation and accumulation of knowledge, coinspired to gain collective creativity and innovative solutions. Realistically, however, multidisciplinary collaboration can be challenging. Thus, design thinking can serve as an effective tool to create a conducive environment for knowledge exchange between heterogeneous disciplines and facilitate collaboration.

Design thinking emphasizes the accomplishment of thinking and learning by doing, and it is embodied through the activities of the process. The Double Diamond design process, developed by the British Design Council [30], proposes four main steps for this process: discover, define, develop, and deliver. It identifies and defines problems for which solutions can be developed and delivered. The design-thinking process adopted by the Hasso Plattner Institute of Design at Stanford involves five phases: empathize, define, ideate, prototype, and test [31]. The design-thinking process for educators, codeveloped by IDEO and Riverdale School, includes five phases: discovery, interpretation, ideation, experimentation, and evolution [32]. Vianna et al. [33] applied design thinking to the generation of innovative businesses and divided the creation process into four phases: immersion, analysis and synthesis, ideation, and prototyping. Generally, the design-thinking process includes three main phases: inspiration, ideation, and implementation [34]. The activities in the inspiration phase focus on understanding the phenomena and the associated problems, systematically sorting-out the collected findings, and identifying a brief design that can be taken to the next stage. The goal of the ideation phase is to promote collective creativity and stimulate idea generation and selection. This phase emphasizes the integration of different views to generate ideas and prototypes for visualizing the concepts. Iterative prototyping is the process of constructing and transforming meanings by growing early conceptual designs into mature outcomes (e.g., products, services, environments, and experiences). During the implementation phase, it is necessary to implement the resulting prototype to verify the proposed solution through demonstration and testing.

The process of design thinking involves a series of iterative divergent and convergent processes. Divergent thinking refers to generated ideas as well as the collection of already existing data, such as research data, interviews, and related information [27]. Convergent thinking considers the outputs of divergent thinking in a meaningful way for making choices [35]. Visualization is fundamental to support divergent and convergent thinking and facilitate collaboration with coconstructed knowledge [36]. Design thinkers are characterized by their capacity to visualize and use prototypes to explore, define, and communicate $[37,38]$. Visualizations can be in 2D or 3D formats that comprise textual and visual elements, including diagrams, sketches, drawings, and mockups [39]. The creative acts of making are particularly significant in design thinking for visualizing the concepts, evoking discussion, and testing hypotheses [40]. Additionally, visual inquiry tools are utilized to organize information visually to allow team members to jointly and democratically explore and define the given problem and develop potential solutions [41]. A visual inquiry tool (e.g., customer-journey map (CJM) and service design blueprint) is usually 
represented in a template that frames the elements of a specific inquiry and creates a visual problem space in which team members can collectively structure and share information. The application of visualization tools is a part of the design-thinking process that is particularly utilized to support collaborative discussion and cocreation processes. Thus, research through design can be adopted to reveal how to implement visualization techniques to facilitate collaboration between multidisciplinary team members while providing experiential knowledge to practitioners of design thinking and related processes.

\subsection{Technology for Enhancing Visitor Experiences in Cultural Attractions}

Traditional marketplaces as historic heritage assets have the potential to become tourist attractions. The local characteristics of these places reflect the history, lifestyles, and cultures of local society. The creation of an experience to make these places more appealing to tourists is essential to the transition process [42]. The quality of experience at a destination has a positive effect on the perceived value and influences the visitor's satisfaction and behavioral intentions $[43,44]$. While designing strategies for sustainable heritage development, visitor experiences should be closely considered. The experience that visitors seek in the heritage context can involve leisure, culture, education, and social interaction [45]. Cultural heritage attractions are experiential products that can facilitate feelings of enjoyment, psychological comfort, involvement, and education [46]. Kim et al. [47] proposed an experience quality scale with seven factors: hedonism, meaningfulness, involvement, local culture, knowledge, novelty, and refreshment. McKercher and Du Cros [48] identified features contributing to successful cultural attractions, including effective storytelling, making the asset "come alive," rendering the experience participatory, making it relevant to tourists, and providing a sense of authenticity. These findings offer practical strategies for the management of a cultural attraction and the enhancement of visitor experience.

A cultural heritage site "comes alive" if it can communicate its rich historical background. While several tactics have been used to transform historic sites into cultural attractions, information and communication technologies (ICTs) provide key tools for communication while offering a more engaging journey for visitors. Hiramatsu et al. [49] developed a beacon-based mobile application that provides historical or cultural information about the temples and shrines in Nikko to trigger young people's interest in the cultural site. The study empirically proved that young people who received basic information relating to Nikko from the application were more active and engaged in Nikko. Researchers have found that the on-site involvement of visitors positively influences their experiences at cultural attractions [50,51]. In the tourism context, involvement refers to the extent to which a tourist is interested and engaged in on-site activities and their affective responses that are aroused from the activities. Zatori et al. [52] revealed that a higher level of experienceinvolvement leads to personal interpretation and contributes to the perceived authenticity and memorability of the tourist experience. Hence, they suggested that tourism service providers introduce interactive elements in the destinations to deepen visitors' on-site experiences. Integrating ICTs in a heritage tourism context can enable a destination that offers rich immersion via the physical and digital landscapes available [53]. This context-aware information can facilitate visitor understanding of the site and encourage their participation at the destination [54]. The use of technologies in the destination to augment visitor experiences benefits the sustainable development of the attractions [55]. Technological innovations, such as mobile guides [56], augmented reality [57], internet of things [58], and quick-response (QR) codes [59], help foster the learning value of historical sites and cultural attractions by bridging the gap between physical and digital worlds.

QR codes and visual makers have been widely adopted as low-cost interactive applications to provide related information to visitors and allow the creation of interactive, personalized, and dynamic experiences [60]. By scanning the code using their mobile devices, visitors can access information about artifacts while linking audio and video explanations of objects. Solima and Izzo [59] demonstrated how new information technologies could enhance the cultural heritage experience by introducing QR codes along tourist 
routes between the Palace of Naples (Italy) and the Villano Palace in Warsaw (Poland). In addition to cultural heritage sites, $\mathrm{QR}$ codes are used in botanical gardens to provide visitors with information about plants and facilitate their appreciation of nature [61]. Drawing on visual recognition technology, more visual experiences have been developed to offer visitors relevant information and engage them in novel interactive activities [62]. Studies comparing interactions provided by QR codes and other visual makers have revealed preferences for the latter because visual makers present context clues and aesthetics [63]. The use of visual makers with mobile applications opens new opportunities to exploit the capabilities of mobile devices. For instance, interactive gamified activities, such as treasure hunts and puzzles, invite visitors to explore sites and enjoy compelling experiences. For example, the Oslo Norsk Telemuseum and Art Gallery proposes riddle-solving or quiz-answering activities to guide visitors in identifying paintings and familiarizing themselves with artworks.

The application of technology provides a promising way to enrich on-site activities that enable visitors to construct their own meaning and experience at cultural destinations. However, little attention has been paid to places like Herb Lane, which is transforming from a traditional market to a historical site to adapt to the changing world. Although promoting traditional markets as cultural attractions to sustain cultural and economic activities is meaningful, the integration of technology into traditional markets to enhance visitor experience is bound to increase the impact.

\section{Methodology}

This article presents a participatory case study that involved the application of a design-thinking process to explore the use of technology to enhance the visitor experience of Herb Lane, with the hopes of expediting the transition from a depressed marketplace to a cultural attraction while revitalizing the region. The notion of the RtD approach is to engage in design practices to link knowledge from research to practice [64]. The author of this paper was both a participant and a researcher and led a multidisciplinary team involving the university faculty and students from the design, computer science, and TCM departments. The team collaborated with shop owners in Herb Lane and an experienced traditional Chinese physician to address the real-world situation. This approach allowed us to involve participants, local groups, and stakeholders to address specific issues in context. Researchers can obtain rich contextual data and gain experiential knowledge on how to apply the design thinking process to drive multidisciplinary collaboration to address real-world problems. Figure 1 illustrates the design thinking process used in this study, according to the previously outlined models of design thinking processes. The process comprises three key phases-inspiration, ideation, and implementation-in which design methods and visualization techniques were adopted to stimulate divergent and convergent thinking. The data collected for this study include direct and participative observations, the outputs generated at each stage, and the data obtained from a field trial study. Results of this study include a qualitative description of the design thinking process and a quantitative evaluation of the effects of the generated solution on the visitor experience in Herb Lane. 


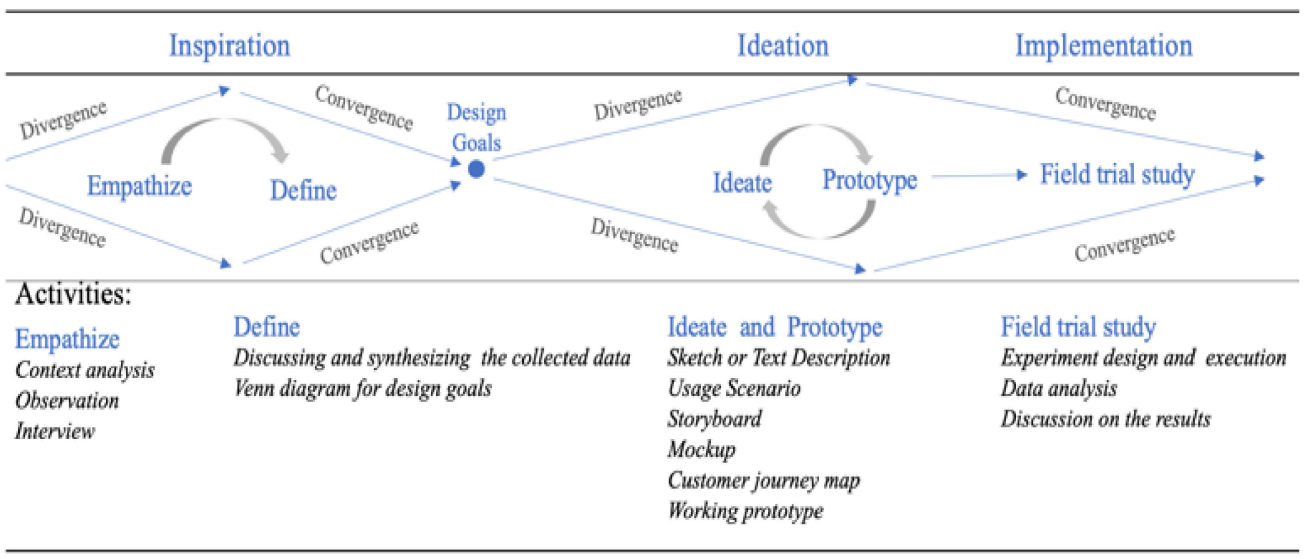

Figure 1. Stages of the applied design-thinking process.

\section{A Participatory Case Study}

\subsection{Inspiration Stage}

During this stage, we first tried to understand the challenges of business owners and visitor experiences in Herb Lane. Research methods, such as context analysis, observations, and interviews, allowed us to be involved in the context and empathize with visitors and business owners. Initially, we interviewed six business owners to understand the development and challenges of Herb Lane's business. Then, we observed the visitors' behaviors and performed interviews to map the existing customer journey. We found that many young visitors roamed the place without making purchases. The journeys of younger visitors through Herb Lane were quite short, involving few interactions with shop owners. From the interviews with visitors, we learned that many young visitors came to Herb Lane because it was recommended by the tour guides and the internet. However, they were unfamiliar with herbs and had no idea about how to incorporate them into their daily lives. According to business owners, one of their concerns is that the traditional herbs cannot attract young consumers and that the marketplace is in decline.

We discussed and synthesized all the gathered information. The major problem identified was how to connect young visitors to the context of Herb Lane and enrich their visiting experiences. The uniqueness of the herbal marketplace, traditional herbs, and herbal culture/wisdom were identified as distinct local characteristics. A Venn diagram was used to discuss the opportunities for any two or all of the characteristics. As illustrated in Figure 2, we mapped out three design goals in Figure 2: engaging visitors in the market and traditional herbs, integrating the herbal culture and wisdom into the marketplace, and increasing visitors' interest in the culture and use of herbs for therapeutic and culinary purposes.

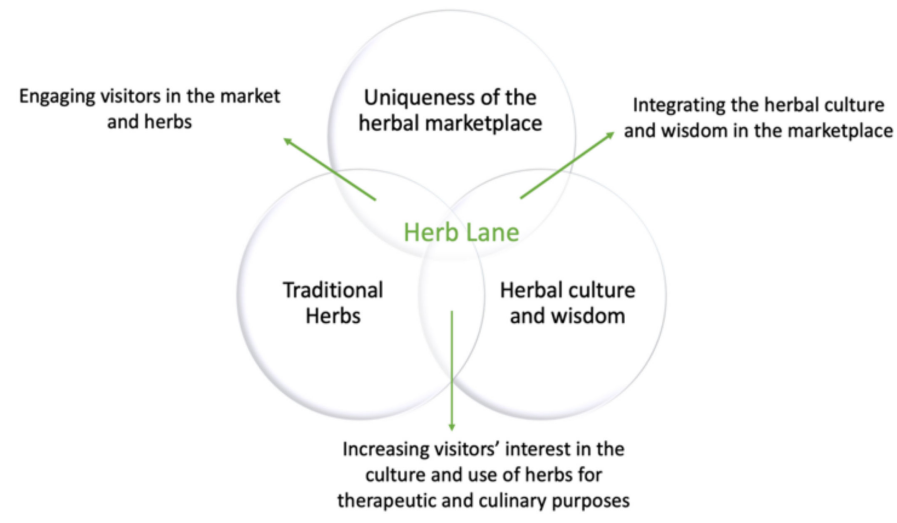

Figure 2. Integrating herbal culture and wisdom into the market place. 


\subsection{Ideation Stage}

The problem definition and design goals guided the second phase: ideation. The multidisciplinary team worked together to brainstorm ideas. Individuals were encouraged to write ideas on Post-it notes and speak freely about potential solutions. The generated ideas ranged from practical solutions to innovative and exotic ones. The ideas and prototypes were interactively refined based on feedback from team members, shop owners in Herb Lane, and an experienced traditional Chinese physician. Having multiple disciplines, including interaction design, computer science, and traditional Chinese medicine, was thought to stimulate creative ideas, which involved ideas that created interactive installations and mobile applications based on traditional diagnostic methods of TCM: inspection, auscultation, inquiry, and palpation. TCM practitioners use the four diagnostic methods to assess a person's body constitution and give proper dietary recommendations. In TCM diagnoses, inspection consists of observing a person's vitality, appearance, complexion, and physical condition. Auscultation involves listening to voice, speech, and respiratory sounds. Inquiry refers to an analysis by asking questions about the person's past health and habits. Palpation involves pulse examination and general touching or probing of the body. The diagnostic methods inspired us to brainstorm design concepts augmented by interactive technologies that enabled visitors to understand their body constitutions and obtain personal herbal remedy advice via interactive installations or their mobile phones. The ideas were visualized in graph-based prototypes (e.g., usage scenarios, storyboards, and sketches) to depict the functionality and scenarios of the conceptual design, as illustrated in Figure 3. The visual prototypes served as vehicles for expression, interpretation, and discussion. The participants quickly and specifically communicated the new experience of the design and improvement, constantly collected feedback, and modified the concepts to meet the design goals. The observation echoes past research [38,65], which found that the visualization of the design process helps to share and communicate ideas, creates common understanding, enables focused discussion, and speeds up innovation.

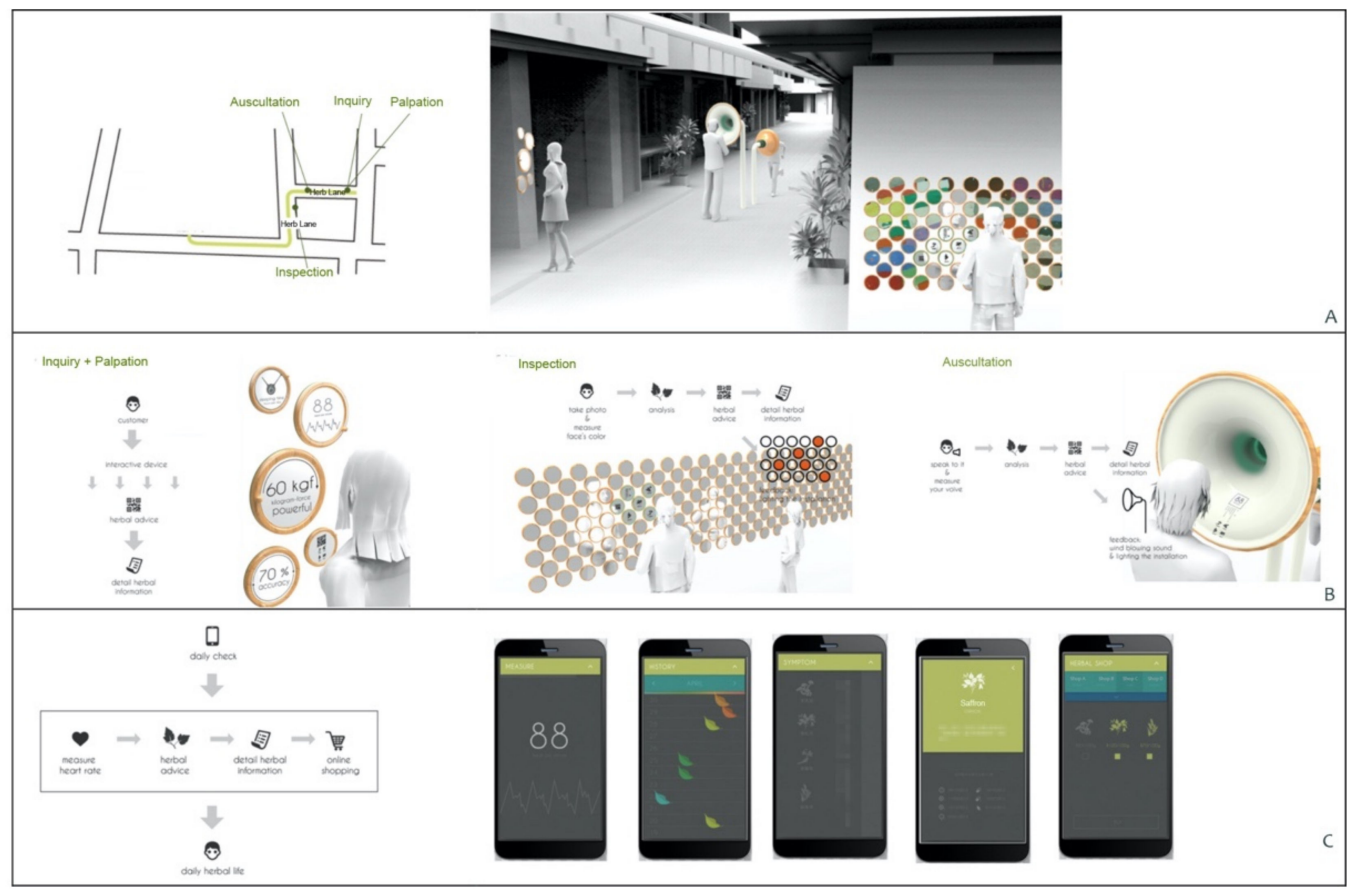

Figure 3. Graph-based prototypes utilized in the ideation stage. (A,B) Inspired by TCM diagnoses, the team members came up with a series of interactive installations embedded with sensors that could assess a visitor's body constitution through interaction and offer proper herbal recommendations as feedback. (C) Based on TCM, a mobile application was proposed to analyze a user's heart rate history and offer suitable herbal recommendations. 
The iterative ideating - prototyping — refined loops helped the transition from having many concepts to focusing on a feasible concept that reached consensus among the team members and stakeholders. The process led to a solution that involved developing a mobile application and herbal labels for herb finding, with visual recognition functionality. Visitors obtain personal herbal recommendations by answering a series of questions and are then invited to find the recommended herbs in Herb Lane with the aid of mobile visual recognition technology. We visualized the visitor experience using a CJM, which is a method for designing customer experience, illustrating how a customer interacts with a service and identifying the possible points of contact (touchpoints) that may be encountered in the service [66]. As shown in Figure 4, the CJM depicts the sequential stages and possible touchpoints that visitors may go through when engaging with the developed mobile application. The touchpoints include physical objects (e.g., herbs, herbal labels, and physical shops), virtual interfaces offered by the mobile application, and people with whom visitors would interact, such as shop owners and attendants. In the planned CJM, the visitor experience, involving engagement with the mobile application, was structured into five key stages: approach, receiving personal herbal recommendations, finding herbs, checking results, and obtaining herbal recipes. The visitor experience is described in more detail below. A working prototype was also developed for the implementation stage.

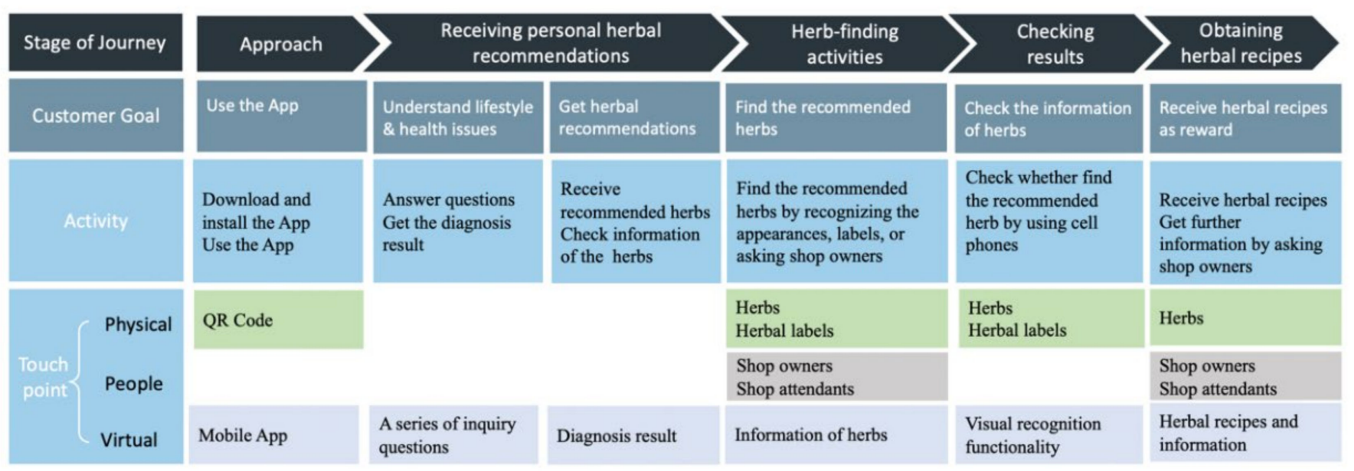

Figure 4. Customer journey map.

\section{(1) Approach}

The visitor can download and install the developed mobile application through QR codes at the entry of Herb Lane.

\section{(2) Receiving Personal Herbal Recommendations}

The mobile application first requires the visitor to answer a series of questions to offer herbal recommendations based on their answers. This idea was adopted from the inquiry diagnosis in TCM. We collaborated with an experienced traditional Chinese physician to develop a series of questions to understand a person's lifestyle in modern life and offer the appropriate herbal recommendations for each lifestyle. The developed questions involved the following: Do you tend to lose your temper? Do you often feel tired? Do you exercise regularly? Do you have business meals often? Do you hang out with friends on a regular basis? Do you lose your appetite or taste often? Do you often play e-sport? Do you care about your appearance? After answering the questions, the visitor will be notified of their lifestyle and herbal remedies. For example, a person who tends to lose their temper, always feels tired, has many business meals, and loses appetite or taste may live a stressful life and may have certain health issues. The mobile application will provide remedies for cultivating their health and recommend suitable herbs that can be found in Herb Lane.

(3) Herb-Finding Activity

According to the visitor's lifestyle, the mobile application will recommend suitable herbs by displaying their names and images. The visitors are then invited to find the herbs in Herb Lane. The images of the herbs give hints to visitors to find the recommended herbs. 
We drew a series of herb images to highlight their features (Figure 5A). As many visitors have mentioned that some herbs looked the same to them, a herbal label, with its name and image, can assist the visitors in identifying herbs and learning about them. Furthermore, the herbal labels will serve as reference images for visual recognition functionality. By scanning a herbal label with their mobile phones, visitors will get information related to the herbs. After testing the feasibility of visual recognition in a real-world setting, the herb labels with a dark background (Figure 5B) worked well under variable lighting conditions and were used in the herb shops, as shown in Figure 5C.
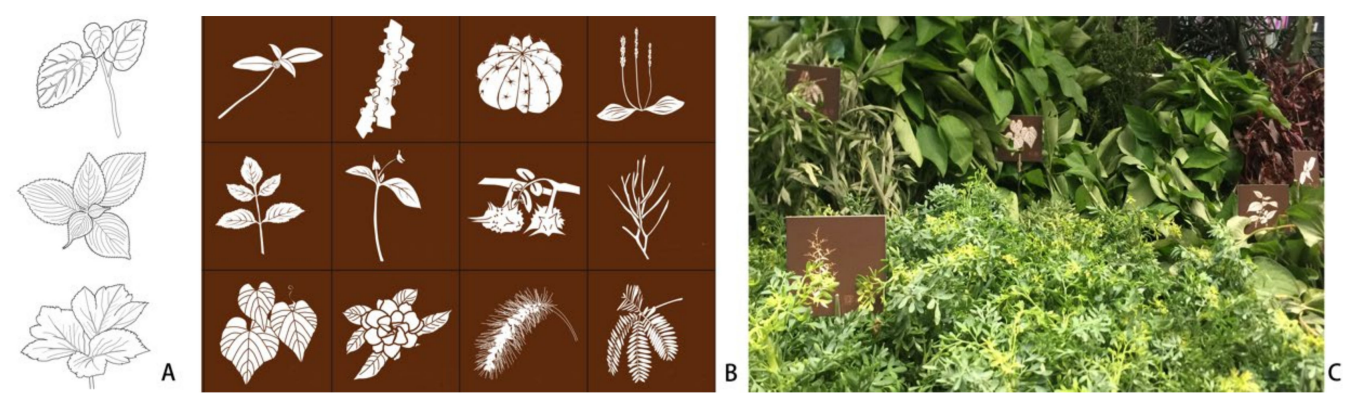

Figure 5. (A) Images of herbs. (B) Herbal label with a dark background. (C) Herbal labels included in the herbal shops.

\section{(4) Check Results}

The herb-finding activity encourages visitors to search for the recommended herbs. Based on image recognition, the application can automatically identify the type of herb and offer herb information (Figure 6). This functionality enables visitors to obtain information about the herbs and check whether they have found the recommended herbs.
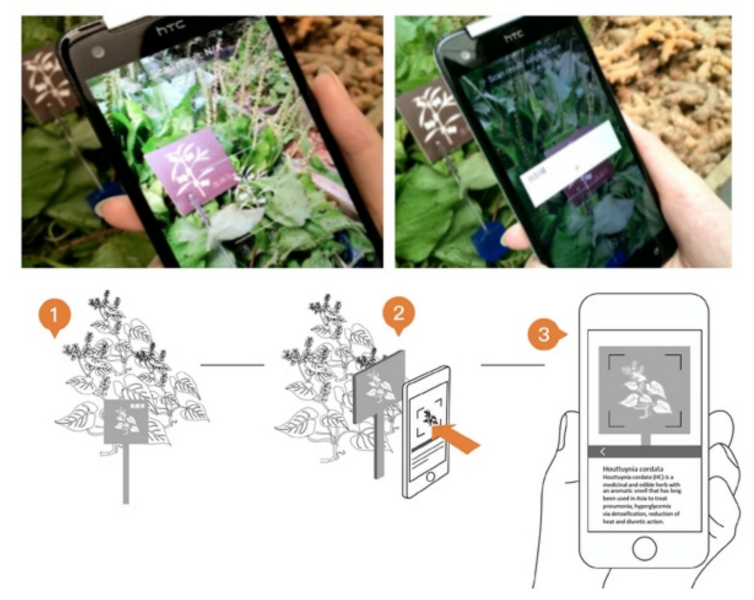

Figure 6. Visual recognition functionality.

\section{(5) Obtain Herbal Recipes}

After the mobile application identifies that the visitor has found the recommended herb, it will notify the visitor and then display a recipe of the herb as a reward. In traditional Chinese medicine, food is an essential component for the prevention and treatment of many diseases. The appropriate use of herbs in diets has long been adopted for health preservation. To adapt to modern life, we collaborated with shop owners to develop a series of herbal recipes that can be easily prepared and incorporated into daily diets, as shown in Figure 7. The recipes give visitors ideas about the application of dietary herbs in their diet and then entice them to try these recipes. 

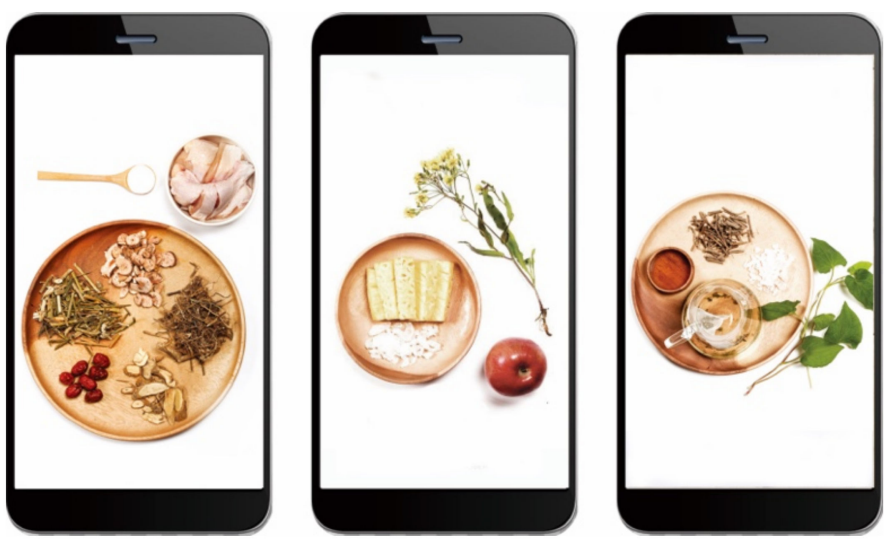

Figure 7. Examples of herbal recipes.

\subsection{Implementation Stage}

\subsubsection{Participants and Procedure}

During this stage, a field-trial study was conducted to help understand whether the proposed mobile application could enrich the visitor experience in Herb Lane. The intended audience for the application was young people, a target group that may not have either a solid background or strong intrinsic motivations for appreciating the value of herbs in Herb Lane. Thus, we recruited young visitors on-site to participate in the study. A total of 114 participants participated in the study. They were randomly assigned to two conditions: the with-app condition and the without-app condition. Fifty-five visitors ( 29 males and 26 females, $25.7 \pm 5.6$ years) in the with-app condition used the mobile application to visit Herb lane, and another 59 visitors ( 27 male and 32 female, $27.3 \pm 4.5$ years) in the without-app condition did not use the application. The field trial study was explained to the participants, all of whom consented to be involved. Participants in the with-app condition were asked to visit Herb Lane with our developed app, downloaded via a QR code at the site. Once the participants completed their tour of Herb Lane, we asked them to fill out a questionnaire and provide feedback on their experience. All participants were thanked and offered a gift certificate.

\subsubsection{Measurement Tools}

The visitor experience questionnaire was a modified version of the tourist experience scale proposed by Kim et al. [47] and focused on four factors of the tourism experience: hedonism, novelty, local culture, and involvement. The hedonism factor consisted of four items: (1) Visiting Herb Lane was pleasurable; (2) I indulged in the activities in Herb Lane; (3) I really enjoyed this tourism experience; (4) visiting Herb Lane was exciting. The novelty factor consisted of three items: (1) Visiting Herb Lane was unique; (2) visiting Herb Lane was different from previous experiences; (3) I experienced something new in Herb Lane. The local culture factor comprised two items: (1) I have a good impression of the local people; (2) I closely experienced the local culture. The involvement factor contained three items: (1) I visited a place where I really wanted to go; (2) I enjoyed the activities that I really wanted to do; (3) I was interested in the activities of this visiting experience. The scores were measured using a set of paper-and-pencil questionnaires, and each item was scored using a 7-point Likert scale, ranging from 1 (very strongly disagree) to 7 (very strongly agree).

\subsubsection{Results and Discussion}

To investigate the effect of the developed mobile application on visitor experience in Herb Lane, the scores of the two conditions on hedonism, novelty, local culture, and involvement were compared using an independent $t$-test. Internal consistency analysis showed that Cronbach's alphas for the four factors were all higher than 0.7, indicating acceptable reliability. The mean scores of all four factors of visitor experience of the participants of the with-app condition were higher than those of the without-app condition. 
The results of independent $t$-test analysis (Table 1) showed that all the differences were statistically significant, and this empirically demonstrates that the developed mobile application can enhance visitor experience in Herb Lane.

Table 1. Mean values and independent $t$-test results for visitor experience.

\begin{tabular}{|c|c|c|c|c|}
\hline $\begin{array}{c}\text { Visitor } \\
\text { Experience }\end{array}$ & Condition & $\mathbf{N}$ & Mean (SD) & T Value \\
\hline \multirow{2}{*}{ Hedonism } & With App & 55 & $5.42(0.86)$ & \multirow{2}{*}{$5.14^{* * *}$} \\
\hline & Without app & 59 & $4.53(1.00)$ & \\
\hline \multirow{2}{*}{ Novelty } & With App & 55 & $5.92(0.86)$ & \multirow{2}{*}{$4.89^{* * *}$} \\
\hline & Without app & 59 & $5.06(0.99)$ & \\
\hline \multirow{2}{*}{ Local Culture } & With App & 55 & $5.50(1.16)$ & \multirow{2}{*}{$3.16^{* *}$} \\
\hline & Without app & 59 & $4.86(0.98)$ & \\
\hline \multirow{2}{*}{ Involvement } & With App & 55 & $5.39(0.93)$ & \multirow{2}{*}{$4.71^{* * *}$} \\
\hline & Without app & 59 & $4.52(1.04)$ & \\
\hline
\end{tabular}

In the follow-up interview, all participants in the two conditions found the visiting experience in Herb Lane novel and enjoyed its distinct cultural atmosphere, suggesting the potential of Herb Lane as a cultural attraction. The results of the field-trial study demonstrate that the use of interactive technology helps enhance the visitor experience. The participants of the with-app condition stated that the use of the mobile application to explore Herb Lane was creative and interesting. The mobile application not only guided their visit to Herb Lane but also allowed them to acquire basic information about herbs. They noted that the mobile application raised their awareness of the therapeutic and culinary uses of traditional herbs. They used to associate traditional herbs with older generations, but the recommendation system and herb recipes changed their attitudes toward herbs. Considerable evidence indicates that people pay more attention to information relevant to themselves compared to information relevant to other people [67]. The personal herbal recommendations based on a visitor's lifestyle can trigger his/her interest in herbs and increase his/her participation in the herb-finding activities.

According to previous research [50-52], visitor experience is affected by the level of their involvement and their connection with the destination. The participants receiving personal herbal recommendations offered by the mobile application perceived the herbs as being self-relevant and exhibited an active interest in herb-finding activities. During the herb-finding activity, the mobile application enabled the participants to access information about the herbs by scanning their labels. After finding the recommended herbs, the participants wanted to acquire more information about the herbs. Hence, many participants in the with-app condition proactively asked the shop owners questions regarding the properties of the herbs and how to consume the herbs. The tourists who seek a deeper understanding of a new culture will be excited about having this new experience [68]. Feedback from shop owners pointed out that they were glad that the young visitors came to ask them questions, giving them the chance to communicate with young visitors. "Human contact" is crucial in constructing a relationship between shoppers and visitors in existing traditional markets. Therefore, visitors do not only merely walk past attractions but interact with the touchpoints, such as people, objects, and the environment in Herb Lane. The findings resonate with the research of Ebejer et al. [69] in that the interactions of tourists with different elements, namely, interactions with surroundings, interactions with others, or interactions with self/meaning, are relevant to the tourist experience in an urban heritage space. Thus, the integration of technology in a cultural attraction should guide visitors to interact with the physical environment, objects, and the local people instead of occupying their attention with a digital device. The herb-finding activity, being 
flexible and for self-discovery, contributes to the formation of personal meaning and to the perceived uniqueness of the experience. It is noteworthy that personal relevance is an essential characteristic of involvement [70]. Thus, while designing an on-site activity, tourism practitioners must consider whether the activity is relevant to the target visitors in order to enhance their involvement.

\section{Conclusions}

Revitalization of traditional marketplaces is pivotal in urban planning and can be attained by various modes of intervention. Although numerous studies have made an effort to promote traditional markets as tourist destinations to sustain their operation, researchers and practitioners have paid little attention to the application of technology to create a better visitor experience. There has been an increasing interest in exploring how the use of technology can augment visitors' engagement with cultural attractions, such as museums and heritage destinations. This study used Herb Lane, a distinct traditional market in Taipei, as a subject to explore the potential of technology in traditional markets to enhance visitor experience. To facilitate visitors' positive experiences in a cultural or historic place, enhancing their participation in a real-world site to explore or understand the cultural significance of the objects is recommended. The developed mobile application provided personal herbal recommendations and herb-finding activities. Inspired by the inquiry diagnosis in TCM, the mobile application offered personal herbal recommendations based on the participants' answers to a series of questions. The personal herbal recommendation made the herbs relevant to the visitors and triggered their curiosity. The herb-finding activities guided the visitors to explore the herbs on site. The features that make the destination relevant to tourists and make the experience participatory contribute to successful cultural attractions [48]. The mobile application was evaluated through a field trial study, and the results indicated that the developed solution could significantly enhance visitor experience in terms of hedonism, novelty, local culture, and involvement.

The solution was made possible through multidisciplinary collaboration. The herbal recommendation system, inspired by TCM practice, and the herb-finding activities, supported by visual recognition technology, required people from different disciplinary perspectives to work together. Moreover, the content regarding self-diagnosis questions, herb recommendations, herb properties, and herb recipes came from the collaboration between the multidisciplinary team members and relevant stakeholders. Therefore, in the attempt to use technology to revitalize traditional markets, program initiators and practitioners must bring together individuals from various and relevant disciplines to collaborate with stakeholders for the continuity of traditional culture and trading activities in the markets. The design-thinking process serves as a platform for multidisciplinary collaboration and the development of creative and communication skills.

This study has implications for both tourism research and practice. In tourism research, this study contributes to the increasing discourse on the application of design thinking in tourism. The use of the design thinking approach in tourism introduces the notions of creativity and multiple disciplines to address the complexity of sustainable tourism development. Design thinking as a learning-by-doing approach is action-oriented. Emerging researchers advocate introducing methods and tools from design science in tourism research, but until now, there has been little research on how they should put this approach to use. This RtD research is expected to fill the gap in the introduction of design thinking in tourism research. Research adopted in the RtD approach should be encouraged as it will provide knowledge of operational significance for its practice.

Regarding practice, this study responded to the rising demands for cultural institutions to integrate new technologies to enhance visitor experiences through tackling the challenges in a real-life situation. In practicing design thinking, the use of visual methods can support the collaborative communication and cocreation process. Effective collaboration between people from various disciplines is crucial to maximizing the potential benefits of multidisciplinarity collaboration. We found that the use of visualization 
techniques is necessary to create a shared space for the exchange and development of communication skills to proceed with the process. The design activities in each stage require visualizations with different characteristics. To support divergence (i.e., problem exploration or ideation), visualization methods in flexible formats are useful to express the ideas of team members. For example, Post-it notes, sketches, and storyboards allow them to capture their abstract concepts in text or images that are more native to the way our brains actually work. Furthermore, making the abstract concepts vivid enables the continuous sharing, learning, refining, and generation of concepts. Conversely, to support convergence (problem definition or decision making), visual inquiry tools providing templates for specific topics are suitable for guiding team members in discussions and reaching consensus. In this study, SWOT analyses, Venn diagrams, and CJM were adopted to engage the team members in inquiry activities. The team members may not only gain a design mindset through practice experience but may also learn to use visualization techniques to collaborate and communicate with different disciplines.

Although this research led a multidisciplinary team to go through the design thinking process from inspiration to implementation within a real-life setting-Herb Lane-it was mainly based on a single case study. Drawing on this study, more RtD studies are encouraged to explore the use of technology in different destinations with various sociocultural contexts through harnessing design thinking and multidisciplinary collaboration. Moreover, the multidisciplinary team in this study involved members majoring in design, whose visualization skills contributed to the multidisciplinary collaboration. Other areas of future research could focus on a team composition without members from a design background and how the visual methods undertaken in the process can be applied to nondesign-based team members to drive multidisciplinary innovation. The findings can promote the adoption of design-thinking methods in wide situations.

Funding: This research was funded by Ministry of Science and Technology (MOST), Taiwan, grant number MOST 101-2218-E-011 -038 and MOST 102-2218-E-011-018.

Informed Consent Statement: Informed consent was obtained from all subjects involved in the study.

Data Availability Statement: The data presented in this study are available on request from the corresponding author.

Acknowledgments: The author would like to thank all the team members for their invaluable contribution to the "Rediscovering Herb Lane" project, particularly Min Wu, Yun-Fan Chang, Yi-Wen Huang, Kuan-Hung Kuo, and Kailan Huang. Additionally, the author would like to thank three anonymous reviewers for their constructive feedback on this paper.

Conflicts of Interest: The author declares no conflict of interest.

\section{References}

1. Gonzalez, S.; Waley, P. Traditional retail markets: The new gentrification frontier? Antipode 2013, 45, 965-983. [CrossRef]

2. Shakur, T.; Hafiz, R.; Arslan, T.V.; Cahantimur, A. Economy and culture in transitions: A comparative study of two architectural heritage sites of bazars and Hans of Bursa and Dhaka. ArchNet-IJAR Int. J. Archit. Res. 2012, 6, 1.

3. Yi, Y.-M.; Gim, T.-H.T. What makes an old market sustainable? An empirical analysis on the economic and leisure performances of traditional retail markets in Seoul. Sustainability 2018, 10, 1779. [CrossRef]

4. Zakariya, K.; Kamarudin, Z.; Harun, N.Z. Sustaining the cultural vitality of urban public markets: A case study of Pasar Payang, Malaysia. Archnet-IJAR Int. J. Arch. Res. 2016, 10, 228. [CrossRef]

5. Zandieh, M.; Seifpour, Z. Preserving traditional marketplaces as places of intangible heritage for tourism. J. Herit. Tour. 2020, 15, 111-121. [CrossRef]

6. Evers, C.; Seale, K. Informal Urban Street Markets: International Perspectives; Routledge: Abingdon-on-Thames, UK, 2014.

7. Uriely, N. The tourist experience: Conceptual developments. Ann. Tour. Res. 2005, 32, 199-216. [CrossRef]

8. Tung, F.-W.; Wu, M. Rediscover Herbal Lane-Enhancing the Tourist Experience Through Mobile Applications. In Proceedings of the International Conference on Cross-Cultural Design, Toronto, ON, Canada, 17-22 July 2016.

9. Buhalis, D.; Amaranggana, A. Smart tourism destinations. In Information and Communication Technologies in Tourism 2014; Springer: Singapore, 2013; pp. 553-564.

10. Buonincontri, P.; Marasco, A. Enhancing cultural heritage experiences with smart technologies: An integrated experiential framework. Eur. J. Tour. Res. 2017, 17, 83-101. 
11. Kotsopoulos, K.I.; Chourdaki, P.; Tsolis, D.; Antoniadis, R.; Pavlidis, G.; Assimakopoulos, N. An authoring platform for developing smart apps which elevate cultural heritage experiences: A system dynamics approach in gamification. J. Ambient Intell. Humaniz. Comput. 2019, 1-17. [CrossRef]

12. Petrelli, D.; Ciolfi, L.; van Dijk, D.; Hornecker, E.; Not, E.; Schmidt, A. Integrating material and digital: A new way for cultural heritage. Interactions 2013, 20, 58-63. [CrossRef]

13. Robinson, J. Squaring the circle? Some thoughts on the idea of sustainable development. Ecol. Econ. 2004, 48, 369-384. [CrossRef]

14. Seidel, V.P.; Fixson, S.K. Adopting design thinking in novice multidisciplinary teams: The application and limits of design methods and reflexive practices. J. Prod. Innov. Manag. 2013, 30, 19-33. [CrossRef]

15. Lee, H.-K. Revitalising traditional street markets in rural Korea: Design thinking and sense-making methodology. Int. J. Art Des. Educ. 2019, 38, 256-269. [CrossRef]

16. Jernsand, E.M.; Kraff, H.; Mossberg, L. Tourism experience innovation through design. Scand. J. Hosp. Tour. 2015, 15 (Suppl. 1), 98-119. [CrossRef]

17. Volgger, M.; Erschbamer, G.; Pechlaner, H. Destination design: New perspectives for tourism destination development. J. Destin. Mark. Manag. 2021, 100561. [CrossRef]

18. Sándorová, Z.; Repáňová, T.; Palenčíková, Z.; Beták, N. Design thinking-A revolutionary new approach in tourism education? J. Hosp. Leis. Sport Tour. Educ. 2020, 26, 100238. [CrossRef]

19. Phi, G.T.; Clausen, H.B. Fostering innovation competencies in tourism higher education via design-based and value-based learning. J. Hosp. Leis. Sport Tour. Educ. 2020, 100298. [CrossRef]

20. Fesenmaier, D.R.; Xiang, Z. Design Science in Tourism: Foundations of Destination Management; Springer: Berlin/Heidelberg, Germany, 2016.

21. Robbins, P.; Devitt, F. Collaboration, creativity and entrepreneurship in tourism: A case study of how design thinking created a cultural cluster in Dublin. Int. J. Entrep. Innov. Manag. 2017, 21, 185-211.

22. Xiang, Z.; Stienmetz, J.; Fesenmaier, D.R. Smart tourism design: Launching the annals of tourism research curated collection on designing tourism places. Ann. Tour. Res. 2021, 86, 103154. [CrossRef]

23. Zieliñski, G.; Studziñska, M. Application of design-thinking models to improve the quality of tourism services. Zarzdzanie Finans. J. Manag. Financ. 2015, 13, 133-145.

24. Cross, N. Designerly ways of knowing: Design discipline versus design science. Des. Issues 2001, 17, 49-55. [CrossRef]

25. Koskinen, I.; Zimmerman, J.; Binder, T.; Redstrom, J.; Wensveen, S. Design research through practice: From the lab, field, and showroom. IEEE Trans. Dependable Secur. Comput. 2013, 56, 262-263. [CrossRef]

26. Bardzell, J.; Bardzell, S.; Dalsgaard, P.; Gross, S.; Halskov, K. Documenting the research through design process. In Proceedings of the 2016 ACM Conference on Designing Interactive Systems, Brisbane, Australia, 4-8 June 2016; pp. 96-107.

27. Brown, T.; Huppatz, D.J. Design thinking. Harv. Bus. Rev. 2008, 86, 84-92.

28. Martin, R.; Martin, R.L. The Design of Business: Why Design Thinking is the Next Competitive Advantage; Harvard Business Press: Brighton, MA, USA, 2009.

29. Olsen, N.V. Design thinking and food innovation. Trends Food Sci. Technol. 2015, 41, 182-187. [CrossRef]

30. Design Council. What Is the Framework for Innovation? Design Council's Evolved Double Diamond; Design Council: London, UK, 2019.

31. Dam, R.; Siang, T. 5 Stages in the Design Thinking Process. Available online: https:/ /www.interaction-design.org/literature/ article/5-stages-in-the-design-thinking-process (accessed on 4 April 2021).

32. Fierst, K.; Diefenthaler, A.; Diefenthaler, G. Design Thinking for Educators; IDEO: Riverdale, CA, USA, 2011.

33. Vianna, M.; Vianna, Y.; Adler, I.K.; Lucena, B.; Russo, B. Design Thinking:Business Innovation; MJV Technology \& Innovation: Atlanta, GA, USA, 2015.

34. Brown, T.; Wyatt, J. Design thinking for social innovation. Dev. Outreach 2010, 12, 29-43. [CrossRef]

35. Lindberg, T.; Gumienny, R.; Jobst, B.; Meinel, C. Is There a Need for a Design Thinking Process? In Proceedings of the Design Thinking Research Symposium 8 (Design 2010), Sydney, Australia, 9-20 October 2010.

36. Bresciani, S. Visual design thinking: A collaborative dimensions framework to profile visualisations. Des. Stud. 2019, 63, 92-124. [CrossRef]

37. Ewenstein, B.; Whyte, J. Knowledge practices in design: The role of visual representations asepistemic objects'. Organ. Stud. 2009, 30, 7-30. [CrossRef]

38. Whyte, J.K.; Ewenstein, B.; Hales, M.; Tidd, J. Visual practices and the objects used in design. Build. Res. Inf. 2007, 35, 18-27. [CrossRef]

39. Eppler, M.J.; Burkhard, R.A. Visual representations in knowledge management: Framework and cases. J. Knowl. Manag. 2007, 11, 112-122. [CrossRef]

40. Stappers, P.J.; Valentine, L. Prototypes as a central vein for knowledge development. In Prototype: Design and Craft in the 21st Century; Bloomsbury Academic: London, UK, 2013; pp. 85-97.

41. Bresciani, S.; Comi, A. Facilitating culturally diverse groups with visual templates in collaborative systems. Cross Cult. Strateg. Manag. 2017, 24, 78-98. [CrossRef]

42. McKercher, B.; Ho, P.S.; Du Cros, H. Attributes of popular cultural attractions in Hong Kong. Ann. Tour. Res. 2004, 31, 393-407. [CrossRef]

43. Chen, C.-F.; Chen, F.-S. Experience quality, perceived value, satisfaction and behavioral intentions for heritage tourists. Tour. Manag. 2010, 31, 29-35. [CrossRef] 
44. Campón-Cerro, A.M.; Di-Clemente, E.; Hernández-Mogollón, J.M.; Folgado-Fernández, J.A. Healthy water-based tourism experiences: Their contribution to quality of life, satisfaction and loyalty. Int. J. Environ. Res. Public Health 2020, 17, 1961. [CrossRef] [PubMed]

45. De Rojas, C.; Camarero, C. Visitors' experience, mood and satisfaction in a heritage context: Evidence from an interpretation center. Tour. Manag. 2008, 29, 525-537. [CrossRef]

46. McIntosh, A.J.; Prentice, R.C. Affirming authenticity: Consuming cultural heritage. Ann. Tour. Res. 1999, 26, 589-612. [CrossRef]

47. Kim, J.; Ritchie, B., Jr.; McCormick, B. Development of a scale to measure memorable tourism experiences. J. Travel Res. 2012, 51, 12-25. [CrossRef]

48. Ingram, H.; McKercher, B.; Du Cros, H. Cultural Tourism: The Partnership between Tourism and Cultural Heritage Management; Routledge: Abingdon-on-Thames, UK, 2002.

49. Hiramatsu, Y.; Sato, F.; Ito, A.; Hatano, H.; Sato, M.; Watanabe, Y.; Sasaki, A. Designing mobile application to motivate young people to visit cultural heritage sites. Int. J. Soc. Bus. Sci. 2017, 11, 121-128.

50. Hung, K.-P.; Peng, N.; Chen, A. Incorporating on-site activity involvement and sense of belonging into the Mehrabian-Russell model-The experiential value of cultural tourism destinations. Tour. Manag. Perspect. 2019, 30, 43-52. [CrossRef]

51. Wong, I.A.; Tang, S.L.W. Linking travel motivation and loyalty in sporting events: The mediating roles of event involvement and experience, and the moderating role of spectator type. J. Travel Tour. Mark. 2015, 33, 63-84. [CrossRef]

52. Zatori, A.; Smith, M.K.; Puczko, L. Experience-involvement, memorability and authenticity: The service provider's effect on tourist experience. Tour. Manag. 2018, 67, 111-126. [CrossRef]

53. Alabau-Montoya, J.; Ruiz-Molina, M. Enhancing visitor experience with war heritage tourism through information and communication technologies: Evidence from Spanish civil war museums and sites. J. Herit. Tour. 2020, 15, 500-510. [CrossRef]

54. Balducci, F.; Buono, P.; Desolda, G.; Impedovo, D.; Piccinno, A. Improving smart interactive experiences in cultural heritage through pattern recognition techniques. Pattern Recognit. Lett. 2020, 131, 142-149. [CrossRef]

55. Gretzel, U.; Sigala, M.; Xiang, Z.; Koo, C. Smart tourism: Foundations and developments. Electron. Mark. 2015, 25, 179-188. [CrossRef]

56. Rasinger, J.; Fuchs, M.; Höpken, W. Information search with mobile tourist guides: A survey of usage intention. Inf. Technol. Tour. 2007, 9, 177-194. [CrossRef]

57. Tscheu, F.; Buhalis, D. Augmented reality at cultural heritage sites. In Information and Communication Technologies in Tourism 2016; Inversini, A., Schegg, R., Eds.; Springer: Cham, Switzerland, 2016; pp. 607-619.

58. Gomez-Oliva, A.; Alvarado-Uribe, J.; Parra-Meroño, M.C.; Jara, A.J. Transforming communication channels to the co-creation and diffusion of intangible heritage in smart tourism destination: Creation and testing in ceutí (Spain). Sustainability 2019, 11, 3848. [CrossRef]

59. Solima, L.; Izzo, F. QR codes in cultural heritage tourism: New communications technologies and future prospects in Naples and Warsaw. J. Herit. Tour. 2018, 13, 115-127. [CrossRef]

60. Pérez-Sanagustín, M.; Parra, D.; Verdugo, R.; García-Galleguillos, G.; Nussbaum, M. Using QR codes to increase user engagement in museum-like spaces. Comput. Hum. Behav. 2016, 60, 73-85. [CrossRef]

61. Tal, H.M.; Gross, M. Teaching sustainability via smartphone-enhanced experiential learning in a botanical garden. Int. J. Interact. Mob. Technol. (iJIM) 2014, 8, 10. [CrossRef]

62. Ng, K.H.; Shaikh, S.P. Design of a mobile garden guide based on Artcodes. In Proceedings of the 2016 th International Conference on User Science and Engineering (i-USEr), Melaka, Malaysia, 23-25 August 2016; pp. 23-28.

63. Ali, S.; Koleva, B.; Bedwell, B.; Benford, S. Deepening visitor engagement with museum exhibits through hand-crafted visual markers. In Proceedings of the 2018 on Great Lakes Symposium on VLSI, Chicago, IL, USA, 23-25 May 2018; pp. 523-534.

64. Klemm, W.; Lenzholzer, S.; Brink, A.V.D. Developing green infrastructure design guidelines for urban climate adaptation. J. Landsc. Arch. 2017, 12, 60-71. [CrossRef]

65. Kernbach, S.; Nabergoj, A.S. Visual design thinking: Understanding the role of knowledge visualization in the design thinking process. In Proceedings of the 2018 22nd International Conference Information Visualisation (IV), Salerno, Italy, 10-13 July 2018; pp. 362-367.

66. Jesus, C.; Alves, H. A customer journey approach. In The Routledge Handbook of Service Research Insights and Ideas; Routledge: Abingdon, UK, 2020; p. 344.

67. Zhang, X.; Ding, X.; Ma, L. The influences of information overload and social overload on intention to switch in social media. Behav. Inf. Technol. 2020, 1-14. [CrossRef]

68. Chen, H.; Rahman, I. Cultural tourism: An analysis of engagement, cultural contact, memorable tourism experience and destination loyalty. Tour. Manag. Perspect. 2018, 26, 153-163. [CrossRef]

69. Ebejer, J.; Smith, A.; Stevenson, N.; Maitland, R. The tourist experience of heritage urban spaces: Valletta as a case study. Tour. Plan. Dev. 2020, 17, 458-474. [CrossRef]

70. Celsi, R.L.; Olson, J.C. The role of involvement in attention and comprehension processes. J. Consum. Res. 1988, 15, 210-224. [CrossRef] 